\title{
Power Quality Control and Management Measures Analysis
}

\author{
Xu Xiangzheng* \\ Department of Electronics Engineering, East China Jiao-tong University, No.808 Shuanggang Road, Nanchang, China
}

\begin{abstract}
This paper presents the power quality problems of the power system and discusses the current situation of power quality management. The various analytical methods and means of power quality are discussed in detail. Depending on the power system harmonic, reactive and negative sequence power quality indicators, this paper expounds power quality indicators treatment methods, and analyzes the prospects for the development of power quality control. Aiming at the shortcomings of the contemporary power quality management, and makes some corresponding countermeasures for improving power quality management level. Power quality management is under the responsibility of government, enterprises and users. Only the government, enterprises and users of the three joint efforts to further improve the power quality of the power system, in order to satisfy the requirements of national economic progress.
\end{abstract}

Keywords: Power system, Power quality control, Power quality management.

\section{INTRODUCTION}

Power quality is an important part of the grid quality power supply. With the continuous development of science and technology and the national economy, users have become increasingly demanding good quality power suppy. At the same time, the structure of the modern electricity grid has also undergone great changes, a large number of access to non-linear loads and shock loads, making the electric energy subject to increase pollution [1]. The power supply enterprises cannot shirk responsibility to deliver customers with safe, reliable, high quality power. Power quality is good or bad has significant influence on the customer satisfaction. Therefore, we must make efforts by the management and technology, and effectively improve power quality.

\section{POWER QUALITY PROBLEMS AND MANAGE- MENT SITUATION ANALYSIS}

\subsection{Power Quality Problems}

Power quality is the quality of the power system energy. The ideal energy should be perfectly symmetrical sine wave. Several factors can deviate from symmetrical sine waveform, which have given rise to power quality problems. Strictly speaking, the main measures of power quality are voltage, frequency and waveform. Judging from a general sense of power quality means high quality power supply, including voltage quality and current quality, power quality and power quality. It can be defined as: causes the voltage, current, or frequency deviations electrical equipment failure or not working properly, which includes frequency deviation, voltage deviation, voltage fluctuations and flicker, phase unbalance, momentary or transient overvoltage, waveform distortion (harmonic), voltage dips, interruptions, temporary rise and supply continuity [2].

The highest power quality indexes are defined as follows. (1) voltage deviation. Voltage deviation is the voltage down (voltage drop) and the voltage rise (voltage uplift) collectively. (2) frequency deviation. The frequency of the same quality requirements for the whole network, does not differ between users. All countries have regulations for the standard deviation. (3) voltage unbalances. Voltage unbalance performance standards for the average maximum offset voltage and phase voltage exceed the requirements. (4) harmonics and inter-harmonics. Sine wave voltage or current integer multiple of the fundamental frequency called harmonics. Fractional harmonic sinusoidal voltage or current noninteger containing the fundamental frequency is known as inter-harmonics, less than the fundamental frequency also belongs among harmonics. (5) voltage fluctuations and flicker. Variable voltage refers to the voltage fluctuation in the envelope of rules, or a series of voltage amplitude typically is not greater than 0.9 to 1.1 times the random variation in the voltage range. Flicker relates to the visual impact of the lamp voltage fluctuation control.

Power quality problems caused by the above factors are the following three aspects: (1) nonlinear problems existing in the power system components. Nonlinear problems of power system components include: harmonic generator; the harmonics generated direct current transmission; transmission lines (especially ultra high voltage transmission lines) amplification of harmonics generated by the transformer. In addition, there are factors substation shunt capacitor compensation devices impact on harmonics. (2) non-linear loads. In the industrial and domestic electrical load, a large proportion of non-linear loads, which is the main source of power system harmonics problems. Rectifiers, voltage and 
frequency converter, electric arc furnace, a large number of electrified railway and other widely used non-linear, volatility, impact resistance and unbalanced load, the voltage and current waveform distortion grid or cause voltage fluctuations and flicker and three phase imbalance, and even cause the system frequency fluctuations, voltage interruption, voltage temporarily changed, and voltage transients, resulting in decreased power quality and grid power quality disturbances and cause serious pollution [3]. (3) power system faults and dynamic operation. Fault and dynamic operation of power system operation can also cause power quality problems, such as various short-circuit fault, lightning shock line, human errors, changing the state of the grid failures generators and excitation systems, fault protection device power electronics start-up and operation of power system dynamic device so will result in voltage and current waveform distortion grid or cause a variety of power voltage fluctuations and flicker and other quality problems.

\subsection{Power Quality Management Situation Analyses}

With the application of intelligent network transformation deepening and new technologies, China's power structure has improved steadily, constantly optimize grid performance, has been able to meet the basic needs of power users [4]. However, there are still deficiencies in power quality management, according to statistics, the proportion of power quality management due to power quality problems brought about by non-compliance of more than $60 \%$. The main problems have existed for Power Quality Management as follows. (1) not establish a timely bus voltage substation automation control mechanism. Bus regulation is not timely is the principal cause voltage threshold crossings. (2) lack of small hydropower management system. Small hydropower do not regulate the Internet would lead to $35 \mathrm{kV}$ and $10 \mathrm{kV}$ substation bus voltage more limited. (3) network configuration unreasonable. For example, in recent years, rapid development of urbanization, the original suburb has rapidly developed into a new city center, but the power grid facilities can not keep up, resulting in line-powered radius is too large, direct impact on the reliability and stability of the power supply. (4) grid grassroots management level is low. Data show that when the county level or below the voltage limit is much greater than the superior long-term parent. (5) lack of power grid pollution treatment. Grid itself there are plenty of non-linear loads, shock loads and unbalanced load access systems, power quality poses a serious threat, but these pollution control stage has not been adequate attention.

\section{POWER QUALITY ANALYSIS METHODS}

\subsection{Fourier Transform}

Fourier transform is a power quality analysis in the field of elementary methods. The advantages of fast Fourier transform algorithm are simple. Nevertheless, its shortcomings are as follows: (1) even though it can be time-domain and frequency domain characteristics of the signal characteristics linked to observe, but not organically combines both. (2) only adapt to the deterministic steady signal (e.g. harmonics).
Time-varying non-stationary signals are difficult to adequately describe. (3) short-time Fourier transform (STFT) discrete form no orthogonal expansion, it is sometimes difficult to achieve efficient algorithm; characteristic scale analysis is only suitable for roughly the same process, the process is not suitable for multi-scale analysis and mutation process. (4) fast Fourier Transform (FFT) using the time information conversion is not enough. No signal collision will cause the entire spectrum band spreading; precondition is not satisfied when the condition will have a "side lobe" and "spectral leakage" phenomenon.

\subsection{Wavelet Transform}

Wavelet transform is a multi-scale analysis of digital technology, which through the process of time series analysis from low resolution to high-resolution displays and the overall characteristics of the process of changing the behavior of regional changes. Commonly used wavelet functions are Daubechies wavelets, B wavelet, Morlet wavelet, Meyer wavelet and so on. Benefits of wavelet transform is: a time frequency localization features, especially for the mutation and non-stationary signal analysis signal; signal can be denoising, identification and data compression and reduction. The disadvantages are: the large amount of real-time system operation needs some high-price, high-speed DSP chip; wavelet analysis has the "edge effect", the boundary data processing will take more time, and bring some errors.

\subsection{Prony Analyses}

Prony analysis method and wavelet analysis methods, the signal can be multi-scale decomposition, which also applies to the detection and analysis of power quality disturbances. However, defect analysis method is to calculate the time is too long, so that the application can be contrary to real-time systems, commonly used for statistical analysis of data on offline.

\subsection{Neural Network}

Neural network theory is an enormous amount of information in parallel processing and massively parallel computing foundation. It is both highly nonlinear dynamical system is an adaptive organization systems can refer to the cognitive, behavioral decision making and intelligent control. Advantage of neural networks is: can handle multiple input multiple output system with self-learning, adaptive and other characteristics; needs not establish a precise mathematical model considering only the input-output relationship can be.

Neural network method has the following deficiencies four areas: (1) general neural network algorithm using a gradient algorithm. The optimization process may fall into local minima. (2) the objective function neural network algorithms based on empirical risk, easy to form "over learning" state, generalization lack of capacity. (3) neural network architecture design relies designer prior knowledge and experience. The number of hidden layers and hidden nodes is difficult to determine. (4) Neural Network iterative algorithm cannot control whether convergence and convergence speed. 


\subsection{Support Vector Machine}

Support vector machine (support vector machine, SVM) is a new pattern recognition method based on statistical learning theory established. It is employed in power systems power quality disturbance detection and fault identification. Support vector machine based on a restricted sample of information to find the best compromise between (ERM) in the complexity of the model (structural risk) and ability to find out in order to get the best generalization ability. Support vector machines in front of the multilayer form similar to the neural network, but the network to overcome the inherent shortcomings of multi-layer, it has the following advantages: (1) it is designed for a limited sample of cases, the goal is to get now the optimal solution has not just the information at the optimum value of the number of samples tends to infinity on the statistical sense. (2) algorithm finally get the global optimal solution. (3) algorithm to real problems through a nonlinear transformation to convert to high-dimensional feature space, ensure that the machine has a good generalization ability, but it cleverly solved the curse of dimensionality, making it independent of the complexity of the algorithm and sample dimension. (4) SVM training time is brief, fast. (5) SVM with extreme accuracy, anti-noise robustness.

\section{POWER QUALITY CONTROL}

\subsection{The Main Methods of Harmonic Suppression}

Suppression power harmonic method is divided into two kinds of active and passive type. Proactive is trying to make itself the principal function of power equipment to complete the task. While as little as possible to produce harmonics. Passive is installed on the bus all kinds of passive power filter, active power filter, such as harmonic compensation device. In various filtering devices installed on the bus have been the foremost measures to control the power harmonics [5].

Usually power capacitors, reactors and resistors in accordance with the requirements of a particular function are combined into a passive power filter. The device was a lowimpedance path for harmonic effectively played a harmonic filter filtering effect. Ideally, if the filter is tuned to the needs of the frequency of a harmonic filter, this time showing a zero impedance circuit, filter out the best.

Passive filter cannot only play a filtering effect, but also for reactive power compensation. Although passive filter has a simple structure, low cost, easy maintenance, high harmonics filtering effect is obvious merits, but there are still some shortcomings difficult to overcome. For example, when the system impedance changes and frequency fluctuations, passive power filter may occur in parallel with the system resonance, the filter system does not function properly.

Active Power Filter is a dynamic new power electronic devices to suppress harmonics, reactive power compensation is used, it can change on the size and frequency harmonics and reactive power to compensate for the change, the application can overcome passive LC traditional harmonic power filters and other suppression methods shortcomings [6]. Active Power Filter and traditional passive power filter com- pared with the outstanding advantages: (1) dynamic compensation can be realized, and size can change the frequency and the change in the harmonic reactive power compensation to compensate for changes in the object has a fast response. (2) can simultaneously harmonic and reactive power compensation and reactive power compensation of size can be adjusted continuously. (3) little influence by the power system impedance, the impedance of the system is not straightforward, and the occurrence of resonance. (4) can track changes in the grid frequency. The compensation characteristic is not affected by changes in the grid frequency. (5) either for a harmonic and reactive power compensation source alone, but also the more concentrated source of harmonic and reactive compensation.

To take full advantage of the active power filter (APF) and passive power filters respective advantages, to achieve the expansion of capacity, reduce costs and improve filtering performance purposes, various hybrid power filter. Hybrid Power Filter conventional APF is to withstand the fundamental voltage is removed. The active power filter device only withstands voltage harmonics, which can significantly reduce the capacity of the active filter device, to reduce costs and improve efficiency. Wherein the passive power filter to eliminate higher harmonic components, APF for compensating the low order harmonic components.

\subsection{The Main Methods of Balancing the Negative Se- quence}

Negative sequence of the power supply system problems mainly in the negative sequence current will generators be, asynchronous motors, protection devices, transformers, power lines and communications and other equipment affected [7]. In order to reduce power system negative sequence current, usually several ways to manage negative sequence problems. (1) load scattered on the supply, distribution network planning and construction process, should be carefully collected data, improve customer load research and forecasting nature, careful analysis, consider the load size, grade and power users of electricity size, asymmetric connected to the different distribution network in order to avoid unbalanced loads centralized connection caused imbalance seriously overweight problems. (2) supply lines during the connection process, the use of cross-changing three-phase load is equivalent to the adjustment method, so that the asymmetric load reasonably allocated to each phase, try to make a balance of. In the daily operation of the three-phase distribution transformer load measured regularly tracked and, based on load characteristics, such as low-voltage load increase by seasonal weather, seasonal and peak load in the monitor, the threephase unbalanced line in a timely manner adjustment and load transfer, so that the three-phase balanced operation possible. (3) the asymmetric load on the higher voltage level received power to make short-circuit capacity is large enough connection points. (4) three-phase equilibrium of the device. For three-phase current imbalance, in addition to the power sector as a reasonable allocation of the load, you can also adjust the unbalanced current installed reactive power compensation device which has a reactive power compensation system while adjusting the imbalance in the active current role. 
With the progress of the national economy, there have been many power system capacity asymmetric load, such as electrified railways and $\mathrm{AC}$ arc furnace. Our AC electrified railway power system from $110 \mathrm{kV}$ (or $220 \mathrm{kV}$ ) by the traction power supply relative to the step-down transformer for electric locomotive traction network and single $27.5 \mathrm{kv}$ (or $55 \mathrm{kv}$ ) later. Electric locomotive traction transformers for power supply of this asymmetry in the power system will produce negative sequence current and the negative sequence voltage [8]. Therefore, the electric power systems, electric railway is the impact face large nonlinear dynamic interference unbalanced load. In order to minimize the impact of negative sequence traction load on the power system caused by the contemporary railway using the following methods to reduce the impact of negative sequence. (1) special wiring transformers. In electrified railway, the more frequently used is a three-phase V/V Traction Transformer, and a few Scott Traction Transformer. Traction load, the probability at any time to meet the load is equivalent to two traction arms is small. Nevertheless, the use of a special three-phase traction transformer wiring asymmetrical current or have greatly improved. (2) power supplies at a higher voltage level, improving the power supply capacity. Then the system side shortcircuit capacity greatly is more than the capacity of the substation negative sequence, three-phase voltage imbalance problems can be alleviated. (3) traction substation commutation connection. Injected into the power system as a whole to reduce the negative sequence current component, a variety of traction substation wiring changes should be implemented to link the power systems that are accessing different rotation phase [9].

Although these programs can indeed play a role in solving the problem of load imbalance, but the negative sequence current and has not been fundamentally eliminated. For negative sequence current problems caused due to unequal load. There are three trends. (1) in traction transformer load side phase current and reactive components, based on a set of fast-adjustable asymmetrical impedance constitute negative sequence current and reactive power compensator with the original passive power filter and traction transformers connected to low-voltage side [10]. When the electric traction load increases, it can absorb the negative sequence current and reactive power emitted when electric traction load is reduced, it can absorb asymmetric reactive power, thus ensuring traction transformer load current of pure active side symmetrical current. (2) based on current balance compensation method for solving the balanced transformer, small power transformer balanced two-phase power supply to balance negative sequence has considerable effect. (3) using the same phase power supply system with symmetrical compensation or through the same phase power supply technology. Phase power supply with active compensation technique is based on using the same phase of the full range of singlephase power supply to achieve the three-phase - single phase system with negative sequence reactive comprehensive compensation. Through the same phase power supply technology is electrified railway traction substation power quality control of the final plan, which is based on HVDC technology and set up an AC-DC-AC traction substation supply programs to achieve symmetrical compensation for single-phase loads.

\subsection{The Main Methods of Reactive Power Compensation}

At present, domestic and reactive power compensation device mainly in the following six ways: vacuum circuit breaker switching capacitors, fixed filter + controllable saturated reactor, fixed filter + thyristor regulator reactors, thyristor switched capacitor, voltage compensation device as well as a fixed filter capacitor ++ reactor regulator and so on. These reactive power compensation device has its own advantages and disadvantages, the following terms of security, real-time, life and compensation effects of the above reactive compensation devices are described.

(1) vacuum circuit breaker switching capacitor. The program biggest advantages are the simple structure, low cost, easy maintenance. But can not accurately control the switching time so that reactive power compensation device generates transient over-voltage and over-current in the process of switching capacitor, thus affecting the reliable operation of the capacitor; removal filter device at the time, the high voltage contacts may cause heavy enough, resulting in equipment damage [11]. Because of the capacitor switching limit the influence and switch life, the capacitor cannot be frequent switching. Thus, affecting the dynamic compensation effect.

(2) fixed filter (FC) + controllable saturated reactor. The program by adjusting the saturation magnetic saturation reactor, reactor control output inductive current balance in parallel filter excess capacitive reactive power. The benefit is fixed parallel filter long-term investment and does not require switching to achieve stepless adjustment; but the device itself will generate a lot of high-order harmonic response fast enough. Overload capability is poor. There are a certain loss and a big noise.

(3) thyristor Switched capacitor (TSC). TSC using single phase thyristor or triac comprise anti-parallel AC noncontact switch will be put to one or more groups of capacitors traction online or removal from the traction network. Program uses zero trigger thyristor way. This compensation scheme in accordance with certain optimization mode, multiple sets of a particular design or several filters, fundamental capacitive under each branch, according to the traction load reactive power demand for change in investment capacity of the capacitor, so TSC become classification dynamic reactive power compensation device, while a harmonic filter in the partial tuning, and filter out the harmonic effect adjustable. Its advantages are simple structure, fast response, does not produce harmonics, can achieve zero switching, not as grave as over-voltage vacuum switches. The disadvantage is that each level is equipped with a corresponding thyristor, the filtering effect of the affected system characteristics and input the number of groups, hefty one-time investment.

(4) fixed filter (FC) + thyristor regulator reactor (TCR). Fixed filter device, according to the harmonic requirements of the program design, anti-parallel thyristors in series with the reactor. Changing the thyristor conduction angle adjustable output inductive current, which can be connected in parallel filter excess capacitive reactive equilibrium, comply with the requirements of power factor. The benefit is a longterm investment in fixed filter, without switching, less thyristors, TCR fast response, regulation performance. The disad- 
vantage is that when a large load traction, the reactor current is small, but the no-load or light load, the reactor is at full capacity, reactor loss is relatively large, the reactor current waveform is serious distortion, contains a lot of harmonic components, will cause the power system harmonic currents flowing into the seriously overweight, so it is necessary to install an additional filter means for filtering to make harmonic standards [12].

(5) regulating compensation device. The device consists of a multi-tap autotransformer load tap switch. Control systems and fixed shunt capacitor banks constituted. Real-time measurement by the control system and traction traction substation feeder voltage current transformer exports, according to the calculated actual size control reactive power load tap switch gear up or down, thus changing the fixed compensation branch voltage capacitor bank regulator capacity output, to achieve dynamic tracking compensation. However, by adjusting the frequency of the moderating effect of limiting, regulating how often the switch electrical life is determined by the tap.

(6) fixed filter (FC) + capacitor (TC) + reactor (TL). The device uses thyristor-off, no-load tap adjustment, can take advantage of thyristor mechanical life and electrical life, thus avoiding the disadvantages of the tap changer electrical short-lived. Has a simple structure, easy operation, but the filtering effect by the system characteristics and inputs affects branch.

Reactive power compensation system for the various domestic defects and deficiencies. Advance direction of reactive power compensation is mainly the following two points. (1) the new magnetic valve controllable reactor (MVCR) + fixed mode capacitance compensation. Magnetron magnetic saturable reactor is based on the principle of magnetic bias is adjustable, and its size depends on the output current of the inductive thyristor firing angle $\alpha, \alpha$ is smaller, the larger the control current is generated, the larger the output of the inductive current. Capacitors produced ahead of the reactive current reactors produce lagging reactive current, reactive power according to load size, by changing the firing angle of the thyristor to change the size of the operating current of the windings to control the degree of saturation of the core, changing work inductance winding, reaching smooth adjustment reactor reactive power capacity. (2) active Power Var Compensator (SVG). SVG is a modern power electronic devices for dynamic harmonic suppression and reactive power compensation. With passive static var compensator (SVC), compared with the following characteristics: (a) true dynamic compensation, with a fast response speed, variable load waveform millisecond track in, to achieve the transient harmonics, power factor, voltage fluctuations and negative sequence compensation. (b) continuously adjustable. (c) meanwhile reactive power compensation and harmonic achieve phase unbalance compensation. (d) from power system frequency impedance and impact, resonance does not take place. This technology includes a number of application examples abroad, while still in its infancy in our country. Despite the fact that the technology is relatively high costs and maintenance costs, but in the future of the integrated control of power quality development [13].

\section{POWER QUALITY MANAGEMENT STRATEGIES}

\subsection{Improve Power Quality Management Systems}

For the existence of the power quality management, power quality management responsibility to establish delivery mechanisms, will progressively splitting the power quality indicators, down to the city power supply bureau biotechnology, planning, marketing, scheduling and substation, district power supply bureau etc. [10]. Operating units, and improve power quality management framework. Establish voltage qualification rate index monthly analysis and reporting mechanism, in accordance with the bus voltage substation pass rate at all levels to carry out analytical work index, the more time to find cause voltage limit of causality, and the problems in the management, technology exists to develop corrective measures and plans.

\subsection{Strengthen Power Grid Construction Planning}

Satisfactory overall grid construction planning cannot be only timely information about energy management control, and power quality management can be combined with the network, sharing resources and comprehensive analysis capabilities. Regional differences in the configuration, according to the load capacitive reactive power compensation enough to respond to the peak load demand and normal voltage level. Configuring a volume of inductive reactive power compensation, giving priority to solve some of the regional power grid voltage is abnormal, and the load through line charging larger power substation. Further optimize the substation layout planning, moderate increase in the number substation, $10 \mathrm{kV}$ power lines so the radius can be controlled in a tolerable range, to meet the end of the line voltage quality requirements [14]. Further optimize distribution network planning, power distribution station in accordance with the principle of "small-capacity, multi-distribution point", as provided in the electricity load centers, a reasonable increase in the number of distribution stations, so 380/220 volt lowvoltage power lines at a reasonable radius range to meet end of the line voltage quality requirements.

\subsection{Strengthen the Operation and Management}

Enhanced bus voltage substation automation means of regulation, strengthening the core network and reactive power equipment management, improve the comprehensive system substation voltage and reactive power control, reducing net loss rate, improve economic power dispatch. Strengthen substation reactive power compensation equipment inspection, pre-test and eliminating defects job. Depending on the power grid operation mode and seasonal load changes, timely adjustment setting automatic voltage control [15]. For regional characteristics, in the preparation of annual operating voltage and reactive power operating mode focus on optimizing the way in ensuring the stability of the system security, in accordance with the regional distribution of the optimal voltage and reactive power control principles, to develop reactive power control objectives and strategies for different voltage. 


\subsection{Strengthen the Cause of Contaminated Power Quali- ty Control Efforts}

Use power quality monitoring system to monitor power quality disturbances comprehensive source distribution, a broad survey of the organization of power quality disturbance sources, supervision and guidance of the interference source pollution control user power quality, reduces the impact on other normal user voltage quality. Create an on-line monitoring, regular testing and random checks of combining power quality monitoring system. Nonlinear noise source connected to the grid, power quality assessment should be conducted to fully consider its impact on sensitive and important users select the appropriate supply voltage level and access points, and control devices into the gateway, the source of interference in its perfect governance and through the acceptance, only connected to the grid.

\section{CONCLUSION}

Power quality management is the responsibility of government, enterprises and users. For the government to improve the power quality management system, continuous introduction of relevant regulations and guidelines to meet the needs of contemporary national economic development, in terms of power quality testing to be a clear division of supervision, strengthen the indicators rigorous testing and analysis. To strictly regulate the establishment of appropriate corporate business areas in accordance with relevant regulations and guidelines for government, relevant personnel of the enterprise to control power quality technical training in electrical equipment manufacturing enterprises to provide technical support for the power quality problems for its users, thereby improving the power quality standards. Only the government, enterprises and users of the three multiparty efforts to further improve the power quality of the power system.

\section{CONFLICT OF INTEREST}

The author confirms that this article content has no conflict of interest.

\section{ACKNOWLEDGEMENTS}

This work was supported by the project "Research on the comprehensive control of power quality to coal mine safety of power grid". The project is No. 20142BBG70028. The authors are grateful to the Jiangxi Province Science and Technology Agency of China for their help.

\section{REFERENCES}

[1] Y. Liu, M. Steurer, P. Ribeiro, "A novel approach to power quality assessment: real time hardware-in-the-loop test bed", IEEE Transactions on Power Delivery, vol. 20, no. 2, pp. 1201-1211, 2005.

[2] C. Rui and X. Gang, "Exploration of power quality management", Journal of Shanghai University of Electric Power, vol. 30, no. 4, pp. 25-28, 2014.

[3] J. Zhang, S. Wang, G. An, "Simple analysis of power quality control in tangshan electricity company", Power Capacitor, vol. 28, no. 6, pp. 16-18, 2007.

[4] Y. Wang, "Analysis of power quality monitoring and management", Science and Technology \& Innovation, vol. 9, pp. 48-50, 2014.

[5] G. Wu, "Modern power quality control technology", Technological Development of Enterprise, vol. 33, no. 2, pp. 116-117, 2014.

[6] P. Wang, "Discussing about power quality monitoring technology", Coal Technology, vol. 31, no. 8, pp. 247-248, 2012.

[7] J. Huang, "The power quality management existence question and countermeasure analysis", China Power Education, vol. 18, pp. 104-105, 2012.

[8] Z. Li and M. Wang, "The analysis method of power quality and control technology", Inner Mongolia Petrochemical Industry, vol. 3, pp. 123-125, 2013.

[9] P. Liu, "Power quality management situation and countermeasure analysis", Science Forum, vol. 11, pp. 181-182, 2013.

[10] M. Li, "The power quality management and power measurement technology", Communication World, vol. 2, pp. 83-84, 2014.

[11] C. Dong, and B. Cui. "Analysis of the new national standard for power quality”, Gansu Science and Technology, vol. 12, pp. 12-16, 2011.

[12] X. Yue, "The status quo and prospects of power quality monitoring", Chemical Engineering \& Equipment, vol. 6, pp. 163-165, 2014.

[13] Y. Song and Z. Ying, "Review of power quality monitoring technology", The Age of Electricity, vol. 5, pp. 66-69, 2007.

[14] Y. Wen, "Analysis of power quality monitoring and management", Science and Technology \& Innovation, vol. 9, pp. 48-50, 2014.

[15] X. Ye, "Study on user's power quality control technology", Valley Silicon, vol. 9, no. 3, pp. 4-5, 2013.

Received: September 22, 2014

(C) Xu Xiangzheng; Licensee Bentham Open.

This is an open access article licensed under the terms of the Creative Commons Attribution Non-Commercial License (http://creativecommons.org/licenses/by-nc/3.0/) which permits unrestricted, non-commercial use, distribution and reproduction in any medium, provided the work is properly cited. 